\title{
Development of the Smart Annealing Unit and Analysis of Low-Frequency Conducted Disturbances by Connection to Low Voltage Public Network
}

\author{
Roman Hrbac ${ }^{1}$, Tomas Mlcak ${ }^{1}$, Jan Dudek ${ }^{1}$, Vaclav Kolar ${ }^{1}$ \\ ${ }^{1}$ Department of Electrical Engineering and Computer Science, VSB-Technical University of Ostrava, \\ 17. listopadu 15, Ostrava, Czech Republic \\ roman.hrbac@vsb.cz
}

\begin{abstract}
Within the research activities, the realization team did the complete development of the annealing unit with the aid of modern technology and components, such as the programmable logic controller, industrial $\mathrm{PC}$, and microcontrollers, to secure an intelligent way of switching the power semiconductor switches (SSR relays) with regard to minimizing the low frequency conducted disturbances. The annealing unit has the implemented algorithm for two ways of output power control, i.e. phase control and full wave control. The algorithm of the full wave control is designed in a way so as to arrange the balanced power in the load. By using this way of control, the harmonic emission is almost entirely eliminated, but the influence of the flicker effect will surface.

The article offers a complex view at the annealing unit from the control method perspective, ensuring the correct annealing cycle and subsequent influence of the annealing unit to supply network. It deals deeply with EMC analysis for both ways of designed annealing unit control. The analysis comes out from the experimental measurements on the functional annealing unit prototype.
\end{abstract}

Index Terms-Annealing unit; heating elements; higher harmonics; full-wave control; phase control.

\section{INTRODUCTION}

Due to the fact that annealing process is not a common issue, there is a limited amount of manufacturers involved in the development and production of the annealing units. From the available annealing units, which are on the market, no one fulfils all requirements the users would appreciate. The development of the smart annealing unit was not only focused on the mitigation of disturbance to the supply system, but mainly for the precise and flawless run of the annealing cycle. For this reason, it was necessary to add many diagnostic sensors and algorithms, to provide some intelligence. Using the visualization, the operation is informed in detail about all essential activities. Unlike the competitive annealing units this annealing unit is unique in

Manuscript received 29 January, 2017; accepted 11 May, 2017.

This paper has been supported by the following projects: LO1404: Sustainable development of ENET Centre; CZ.1.05/2.1.00/19.0389 Development of the ENET centre research infrastructure; SP2017/159 and SP2017/97 Students Grant Competition and TACR TH01020426. the fact that best features from various products are all implemented here. The accuracy of the annealing process reaches maximum $\pm 2{ }^{\circ} \mathrm{C}$ in the temperature range $-20{ }^{\circ} \mathrm{C}$ up to $1250{ }^{\circ} \mathrm{C}$. The output heating sections of the annealing unit are short-circuit proof, and are able to disconnect the fault within $10 \mathrm{~ms}$. It is also capable of detecting a disconnected heating element, thermoelement, communication error and other failures. The great asset is the ability of processing the measured data and storing them for later displaying the annealing process. It is also able to communicate using Ethernet, send an email or SMS message and notify the operator about various failures in time. The competitive units are not equipped with user comfort functions, and thus, this annealing unit will be a big competitor on the market.

The development and modernization of the unit was executed within several stages [1] for the company Svarservis, Ltd [2]. The newly developed way of control the annealing cycle, and thereby, reaching the continuous regulation of the thermal power into the heating element is introduced in this article. The developed algorithm ensures smooth current regulation so that the most accurate follow up of the required temperature within the whole annealing cycle is achieved. There was a measurement of the low frequency conducted disturbance performed on the built prototype of the annealing unit. Subsequently, the assessment for different control modes has been made.

\section{MaIn CONTROL Algorithm OF THE ANNEALING PROCESS}

The control units capable of continuous current regulation into heating elements have been developed for smooth regulation of the heating power. The main task of the control units is to produce suitable algorithm for switching the power semiconductor switches (SSR), based on the measured current values and control commands from the superior PLC. The switching of the load is realized via the output power SSR relays, and is executed either by using the phase-control algorithm, or by using the full-wave control algorithm. The prioritized algorithm is the full-wave control, provided that magnitude of load current does not exceed 200 
A. This means that the load current reaches $65 \mathrm{~A}$ in the time of $8.7 \mathrm{~ms}$ after the last voltage zero crossing. Three testing impulses are applied before the initial activation for the reason aforementioned. In the time of $8.4 \mathrm{~ms}$, the SSR relay is closed, and the actual current value is acquired in the time of $8.7 \mathrm{~ms}$ after the last voltage zero crossing. If the value of the first tested impulse current exceeds $65 \mathrm{~A}$, the next testing impulse is not applied, and the phase-control algorithm is directly selected immediately (Fig. 1). On condition that the measured instantaneous current value is lower than $65 \mathrm{~A}$ for the second and third testing impulse, the full-wave control is selected (Fig. 2). This adaptive choice of the control mode enables the connection of various resistance loads. The full wave control algorithm has the capability to apply 32 various combinations of half wave switching within the control period of $320 \mathrm{~ms}$. This is the way of regulating the requested energy at the output, and thus, the controlled temperature of the heating element.

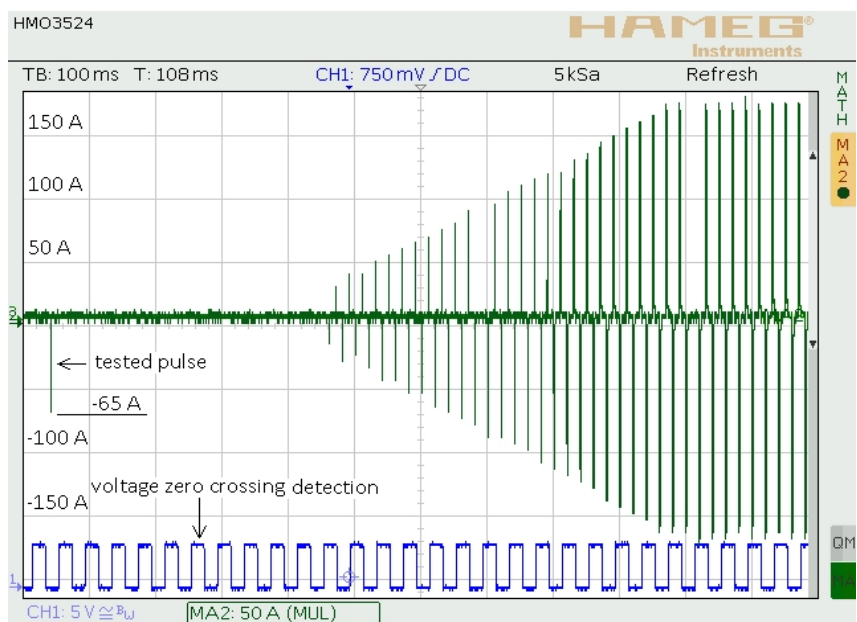

Fig. 1. Start-up of the annealing unit using phase-control algorithm, MA2: a current course, $\mathrm{CH} 1$ : a voltage zero crossing detection.

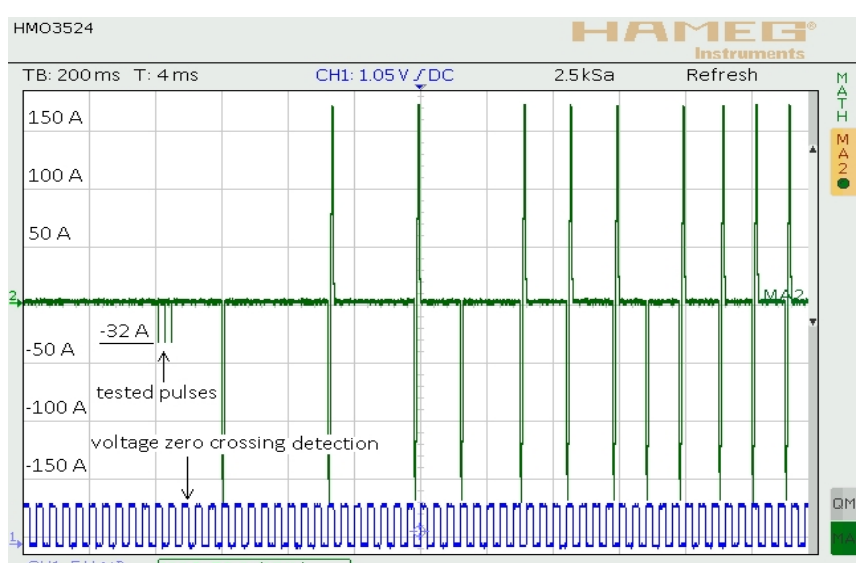

Fig. 2. Start-up of the annealing unit using full-wave control algorithm. MA2: a current course, $\mathrm{CH} 1$ : a voltage zero crossing detection.

The possibility of continuous current regulation is utilized for the newly developed annealing algorithm, which controls the temperature of heating elements in accordance with the requested values.

Due to the use of various sizes and material types, the new algorithm will be able to adjust the parameters with respect to material changes, as different material volumes need different time constants for control. They also have various ratios of thermal mass inertia. The block diagram of this newly developed control algorithm is shown in Fig. 3.

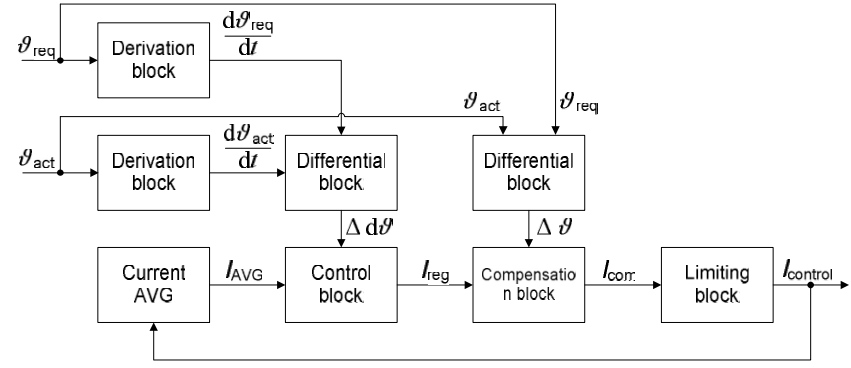

Fig. 3. Block diagram of the annealing control algorithm.

The basic input quantities into the control algorithm are the required annealing temperature $\vartheta_{\text {req }}$ and the actual annealing temperature $\vartheta_{\text {act }}$. The derivation of the required and actual temperature by time is performed and the difference of the derivation $\Delta \mathrm{d} \vartheta$ acts as the main response for the current regulation. By using this value, the correct direction of the temperature change is kept. In order to prevent the deviation of the actual temperature $\vartheta_{\text {act }}$ from the required temperature $\vartheta_{\text {req }}$, the subsequent adjustment based on subtraction of the both temperatures $\Delta \vartheta$ is executed There is a limiting element at the output, keeping the current above the minimum and below the maximum given boundary. The resultant current value $I_{\text {control }}$ which has been calculated by the described technique is directly used as control variable for annealing unit current regulation. The moving average is subsequently calculated from the resultant current value $I_{\text {control. }}$. The value of the current moving average $I_{\mathrm{AVG}}$ acts as the input value for current calculation in the upcoming control cycle.

The origin of this algorithm was very demanding, and several different solutions preceded it. The resultant algorithm was tuned by experimental measurements, and is designed so as to assure the required temperature image during the whole process of the annealing cycle.

The temperature sequence of the annealing cycle for annealing the weld in the light-walled tube is shown in Fig. 4. The actual temperature waveform which overlaps the requested waveform may be seen there. Further, the real annealing current generated by control algorithm is also displayed here.

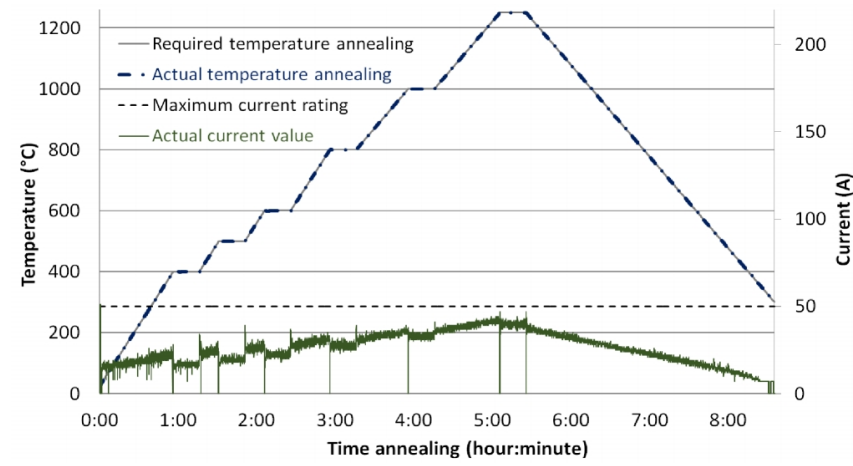

Fig. 4. The sequence of the annealing cycle for annealing the weld in the light-walled tube.

The temperature sequence of the annealing cycle for annealing the weld in the thick-walled tube is shown in 
Fig. 5.

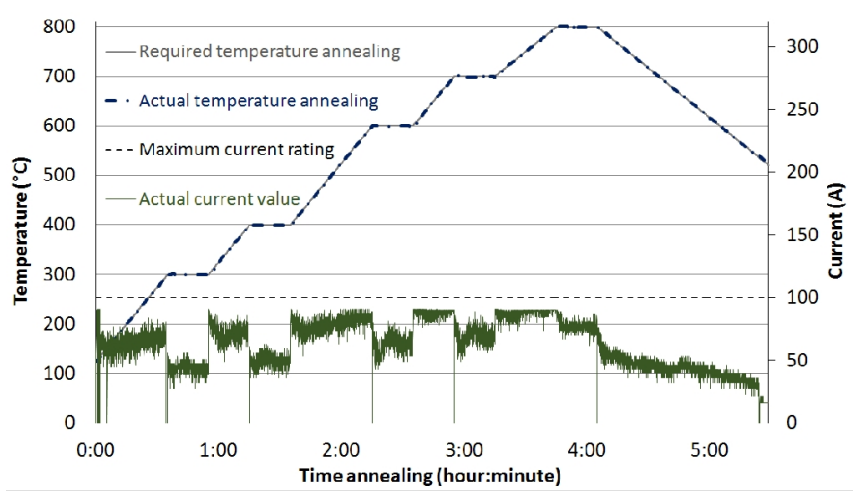

Fig. 5. The sequence of the annealing cycle for annealing the weld in the thick-walled tube.

Similarly, the actual temperature value generated by the newly developed algorithm requirement is seen there also.

\section{LOW FREQUENCY DISTURBANCE FOR INTRODUCED CONTROL ALGORITHMS}

Two possible control algorithms were introduced. Both the algorithms were investigated with regards to possible EMC problems by connecting the annealing unit to public low voltage supply systems.

The full wave control with the designed switching period equal to $320 \mathrm{~ms}$ will have an impact to the low voltage fluctuations and the flicker [3], [4], while the phase control will have an impact to harmonic current emission [5] and should be considered as the unbalanced three-phase equipment.

Generally, the connection of the annealing unit to public low voltage supply system is possible in the following conditions:

- relevant EMC standard requirements [3]-[5] are met, or

- minimum network impedance or $R_{\mathrm{SC}}$ will be stated by the manufacturer, or

- the approval of the distribution network operator (DNO) or user is necessary [3].

With respect to flicker, the reference network impedance is set to $0.15+\mathrm{j} 0.15 \Omega$ for three-phase equipment, which refers to network three phase symmetrical short-circuit current of approx. 1.1 kA (SQ = $748 \mathrm{kVA})$.

The nominal output is $48 \mathrm{kVA}$ for all six sections in service, which is necessary for statement of $R_{\mathrm{SCE}}$ when assessing the harmonic current limits.

As the annealing unit is planned to operate in rural areas, where the typical network impedance is close to reference network impedance, so the minimum network impedance restriction is not feasible, moreover, the prospected end-user is seldom capable to measure and assess the network impedance at the point of connection. The approval of DNO may also be omitted by the end-user.

For the first assessment the model of annealing unit with three sections in service in EMTP-ATP software was created. The model is shown in Fig. 6 and uses TACS Pulse sources for triggering triac models. The transformer data are identical to $400 / 84 \mathrm{~V}, 48 \mathrm{kVA}$ Y-Y transformer.

\section{A. Flicker Effect}

Reference [6] shows the algorithm for functional and design specifications of flicker meters, which may be used for exact assessment of instantaneous flicker.

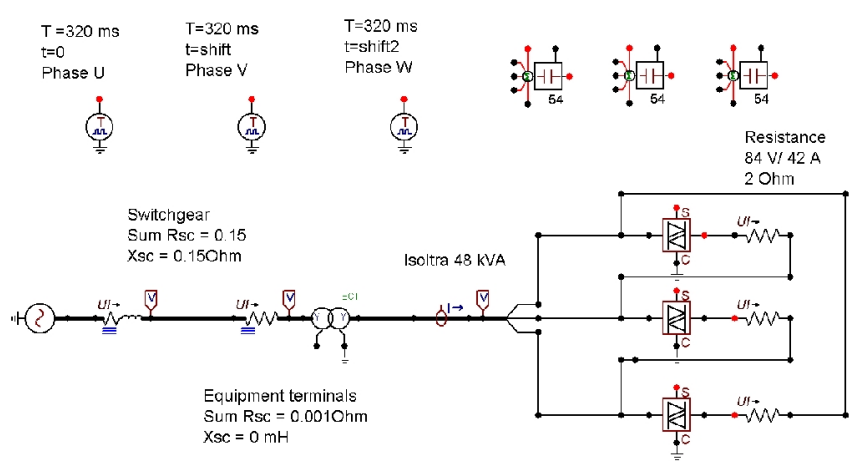

Fig. 6. Model of annealing unit with three sections in service.

This algorithm is complex and not necessary for the quick approximate assessment. As the annealing process may take several hours, with the same heating element connected then by calculation and simulation of the instantaneous flicker $P_{\text {inst }}$, the first evaluation may be obtained from the simulated and calculated values of $P_{\text {ins. }}$.

The voltage changes are solely of rectangular shapes for the full-wave control and thus, there are simplified approaches which may be used.

The analytic method shown in [4], which respects the duration of the voltage changes, is not applicable, if the time between the end of one voltage change and the beginning of the other voltage change is shorter than $1 \mathrm{~s}$. For shorter periods the only applicable is the curve shown in Fig. 7 showing the limit voltage drops, but not taking into account the voltage drop duration (so called shape factor F).

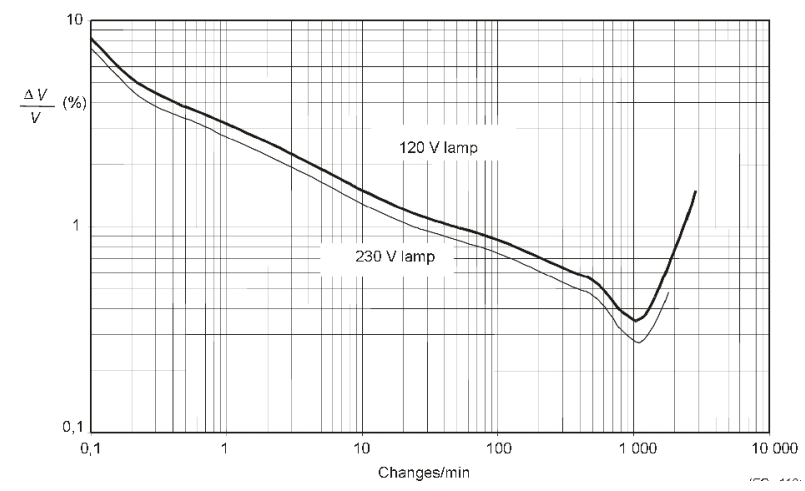

Fig. 7. Pst $=1$ curve for rectangular voltage changes.

Reference [7] shows the algorithm for more precise calculation of the $P_{\mathrm{ST}}$ taking into account both relative voltage change and number of voltage changes per minute, but also the shape factor which respects the duration of the voltage change for rectangular voltage changes even for periods shorter than $1 \mathrm{~s}$. The short time flicker $P_{\mathrm{ST}}$ may be obtained as follows

$$
P_{\mathrm{ST}}=\left(\frac{d}{d_{\mathrm{Pst}=1}}\right) \times F
$$

where $d$ is the relative voltage change, $d_{\mathrm{Pst}}=1$ is the limit 
voltage drop for rect. voltage changes and $F$ is the shape factor (Fig. 8).

The approximate numerical assessment of voltage drops for one phase and three phase equipment may be for lagging current (inductive) load be expressed as

$$
\Delta U_{\mathrm{hp}}=\left|\Delta I_{\mathrm{p}} R+\Delta I_{\mathrm{q}} R\right|
$$

and the relative voltage change is then given be expression

$$
d=\Delta U_{\mathrm{hp}} / U_{\mathrm{n}} .
$$

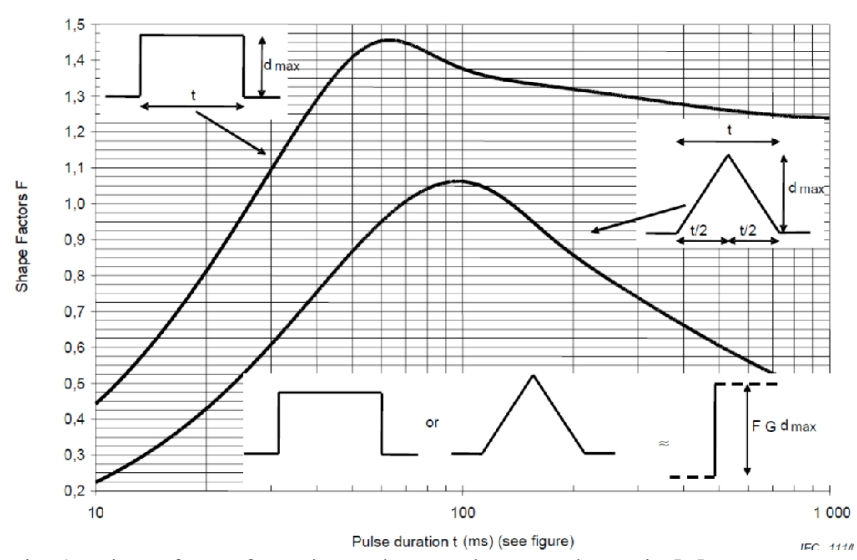

Fig. 8. Shape factor for pulse and ramp changes, shown in [7].

In fact, due to phase to the phase connection, there are twice as many voltage drops as the switching period caused by conducting the current from phase $\mathrm{U}$ to phase $\mathrm{V}$ by triac A and from phase $\mathrm{W}$ to $\mathrm{U}$ by triac $\mathrm{C}$.

The firing impulses into three triacs are delayed by $106.66 \mathrm{~ms}$ and $213.33 \mathrm{~ms}$ to achieve maximum balance in the network current. Moreover, the current drawn from the supply system, as a result of phase to phase voltage is not in phase with phase voltage, but it either lags the voltage by 30 degrees or it leads the voltage by 30 degrees.

As a result, the two voltage drops within one period are not of the same magnitude. For the leading current the individual elements in (2) subtract. As the simplified approach applied by [7] and described in (1) considers only one voltage drop, there are upper and lower limits of $P_{\text {st. }}$.

The upper limits consider both the voltage changes equal to maximum, thus the number of fluctuation changes equal to $375 \mathrm{~min}^{-1}$ ( 4 voltage changes per $320 \mathrm{~ms}$ ), with $\mathrm{d}_{\text {lim }}=0.5$, while the lower limit neglects the smaller voltage drop (caused by leading current), which approx. 3.2 times smaller, and thus, the number of fluctuations is only $187.5 \mathrm{~min}^{-1}$ (2 voltage changes per $320 \mathrm{~ms}$ ), with $\mathrm{d}_{\text {lim }}=0.62$.

The results of the simulation and calculated values of $P_{\mathrm{st}}$ are shown in Table I, where ${ }^{\text {a) }}$ N/A - not applicable - no flicker due to continuous open walve, ${ }^{\text {b) }}$ The $P_{\text {st }}$ is not possible to assess in the simplified way, due to step voltage changes. The $P_{\text {st }}$ limits were possible to assess by aforementioned approach for pulse duration below $100 \mathrm{~ms}$ and over $220 \mathrm{~ms}$, as for pulse width between $100 \mathrm{~ms}$ and $220 \mathrm{~ms}$, there is an overlap of conducting valves, leading to two steps in network current, and thus, two voltage changes. It may be concluded that the values of $P_{\text {st }}$ will be even worse.

TABLE I. SIMULATION RESULTS FOR $2 \Omega$ HEATING ELEMENTS,

\begin{tabular}{|c|c|c|c|c|c|c|c|c|}
\hline \multirow{2}{*}{\multicolumn{3}{|c|}{ Control }} & \multirow{3}{*}{$\begin{array}{c}\begin{array}{c}\text { Loa } \\
\mathbf{d}\end{array} \\
I_{\text {load }}\end{array}$} & \multirow{3}{*}{$\begin{array}{c}\begin{array}{c}\text { Shap } \\
\text { e } \\
\text { facto } \\
\text { r }\end{array} \\
F\end{array}$} & \multicolumn{4}{|c|}{$P_{\text {st }}$ based on assessment } \\
\hline & & & & & \multicolumn{2}{|c|}{ Upper limit } & \multicolumn{2}{|c|}{ Lower limit } \\
\hline$T_{\mathrm{pul}}$ & $d$ & $T_{\text {drop }}$ & & & $r$ & $P_{\mathrm{st}}$ & $r$ & $P_{\mathrm{st}}$ \\
\hline (s) & $(\%)$ & (s) & (A) & $(-)$ & (mi & $(-)$ & $(\min$ & $(-)$ \\
\hline 32 & 0 & 0 & 41.2 & $\mathrm{~N} / \mathrm{A}^{\mathrm{a})}$ & 375 & 0 & 187. & 0 \\
\hline 31 & 0.77 & 10 & 40.5 & 0.42 & 375 & 0.652 & 187. & 0.526 \\
\hline 29 & 0.77 & 30 & 39.2 & 1.1 & 375 & 1.710 & 187. & 1.379 \\
\hline 27 & 0.77 & 50 & 37.8 & 1.4 & 375 & 2.176 & 187. & 1.755 \\
\hline 23 & 0.77 & 90 & 35 & 1.4 & 375 & 2.176 & 187. & 1.755 \\
\hline 15 & 0.82 & N/A & 28.3 & 1.35 & 375 & $\mathrm{~N} / \mathrm{A}^{\mathrm{b})}$ & 187. & $\mathrm{~N} / \mathrm{A}^{2)}$ \\
\hline 90 & 0.82 & 90 & 21.9 & 1.43 & 375 & 2.356 & 187. & 1.900 \\
\hline 70 & 0.82 & 70 & 19.3 & 1.43 & 375 & 2.356 & 187. & 1.900 \\
\hline 50 & 0.82 & 50 & 16.3 & 1.41 & 375 & 2.323 & 187. & 1.873 \\
\hline 40 & 0.82 & 40 & 14.6 & 1.3 & 375 & 2.142 & 187. & 1.727 \\
\hline 20 & 0.82 & 20 & 10.3 & 0.8 & 375 & 1.318 & 187. & 1.063 \\
\hline 10 & 0.82 & 10 & 7.3 & 0.42 & 375 & 0.692 & 187. & 0.558 \\
\hline
\end{tabular}
SYMMETRICAL LOADING, $P_{\mathrm{MAX}}=10.5 \mathrm{KW}$.

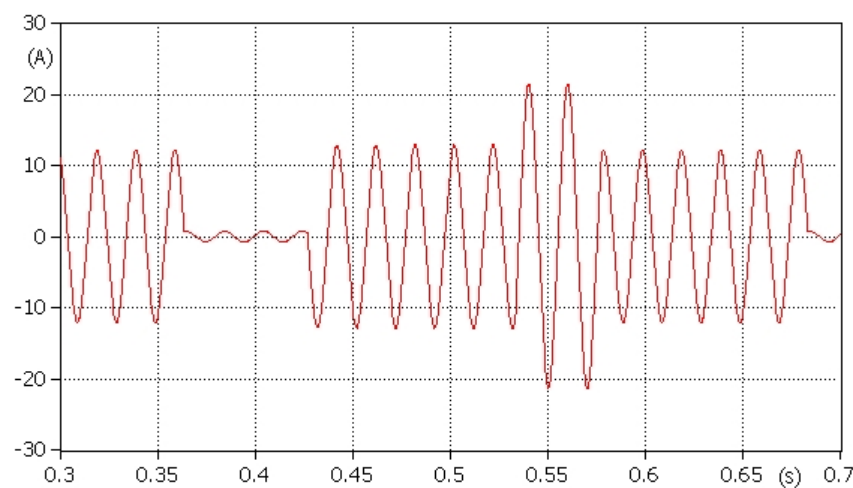

Fig. 9. Phase $U$ simulated input current for full-wave control and pulse duration of $150 \mathrm{~ms}$. The partial overlap of triac A and C conducting phase causes two input currents magnitude, the open time of triac $\mathrm{A}$ and $\mathrm{C}$ results only magnetizing transformer current component.

The expected $P_{\text {st }}$ is between the upper and lower limit. As a conclusion even for $10.5 \mathrm{~kW}$ of heating power the short time flicker will be exceeded, and thus, apart from the difficulties with control loop, this full-wave control is not suitable for direct connection to the distribution network.

\section{B. Harmonic Current Emission for Phase Control}

The numerical simulation of the annealing unit with three sections, with maximum section current of approx. 96 A for phase control was performed.

The maximum input current in this case reaches approx. 35 A (24 kVA). With all six sections in service, the input current would reach $70 \mathrm{~A}$ (48 kVA).

The EN 61000-3-12:2011 covers these types of equipment. As the waveforms of load currents in each section do not have the identical shapes, and are connected between phases, the requirements for hybrid equipment apply. The permissible harmonic currents applicable to this equipment are shown in Table II, if the connection to the supply low voltage is required. As aforementioned, the symmetrical short-circuit power in rural areas is low, only the first row with $R_{\mathrm{SCE}}=33$ ohms applies.

The simulation results for firing angle between 18 degrees and 153 degrees are shown in Table III. It is obvious, that 
for firing angle above 36 degrees the limits will be exceeded. The amount of deformed current and deformed power depending on firing angle is shown in Table IV.

TABLE II. CURRENT EMISSION LIMITS FOR NON-SYMMETRICAL THREE PHASE CONTROL.

\begin{tabular}{|c|c|c|c|c|c|c|c|c|}
\hline $\begin{array}{c}\text { Min } \\
\boldsymbol{R}_{\text {sce }}\end{array}$ & \multicolumn{6}{|c|}{$\begin{array}{c}\text { Permissible current of individual } \\
\text { harmonic } \boldsymbol{I}_{\mathbf{h}} / I_{\text {ref }}(\%)\end{array}$} & \multicolumn{2}{c|}{$\begin{array}{c}\text { Permissible } \\
\text { parameters of } \\
\text { harmonic (\%) }\end{array}$} \\
\hline & $I_{3}$ & $I_{5}$ & $I_{7}$ & $I_{9}$ & $I_{11}$ & $I_{13}$ & $T H C / I_{\text {ref }}$ & $P W H C / I_{\text {re }}$ \\
\hline 33 & 21 & 10. & 7.2 & 3.8 & 3.1 & 2 & 23 & 23 \\
\hline 66 & 24 & 13 & 8 & 5 & 4 & 3 & 26 & 26 \\
\hline 120 & 27 & 15 & 10 & 6 & 5 & 4 & 30 & 30 \\
\hline 250 & 35 & 20 & 13 & 9 & 8 & 6 & 40 & 40 \\
\hline$>350$ & 41 & 24 & 15 & 12 & 10 & 8 & 47 & 47 \\
\hline
\end{tabular}

TABLE III. CURRENT EMISSION LIMITS FOR NON-SYMMETRICAL THREE PHASE CONTROL.

\begin{tabular}{|c|c|c|c|c|c|c|c|c|}
\hline $\begin{array}{c}\text { Firing } \\
\text { angle } \\
(\boldsymbol{\alpha})\end{array}$ & $\begin{array}{c}\text { Simulated } \\
\text { RMS values } \\
\text { of input } \\
\text { currents (A) }\end{array}$ & \multicolumn{2}{|c|}{$\begin{array}{c}\text { Simulated currents of } \\
\text { individual harmonic } \boldsymbol{I}_{\mathbf{h}} / I_{\text {ref }} \\
\mathbf{\%} \%)\end{array}$} & \multicolumn{2}{|c|}{$\begin{array}{c}\text { Simulated } \\
\text { parameters of } \\
\text { harmonic (\%) }\end{array}$} \\
\hline & $I_{1}$ & $I$ & $I_{5}$ & $I_{7}$ & $I_{11}$ & $I_{13}$ & $T H C / I_{\text {ref }}$ & $P W H C / I_{\text {ref }}$ \\
\hline 18 & 34.92 & 34.96 & 2.58 & 2.40 & 1.91 & 1.64 & 4.67 & 8.08 \\
\hline 36 & 33.72 & 33.98 & 8.95 & 6.72 & 2.93 & 2.24 & 12.18 & 15.78 \\
\hline 54 & 30.98 & 31.51 & 14.72 & 7.69 & 5.25 & 4.15 & 18.28 & 23.03 \\
\hline 72 & 26.63 & 27.32 & 17.19 & 9.56 & 6.92 & 5.32 & 22.28 & 35.41 \\
\hline 90 & 21.17 & 22.07 & 18.87 & 16.27 & 10.72 & 5.99 & 28.34 & 45.74 \\
\hline 108 & 15.15 & 16.40 & 31.51 & 17.01 & 12.49 & 9.68 & 38.26 & 58.85 \\
\hline 126 & 9.58 & 11.34 & 49.34 & 25.78 & 18.44 & 14.32 & 53.53 & 77.21 \\
\hline 144 & 4.81 & 6.54 & 66.74 & 49.84 & 21.89 & 17.72 & 67.86 & 98.08 \\
\hline 153 & 3.00 & 4.37 & 69.20 & 58.92 & 35.60 & 25.56 & 72.79 & 108.74 \\
\hline
\end{tabular}

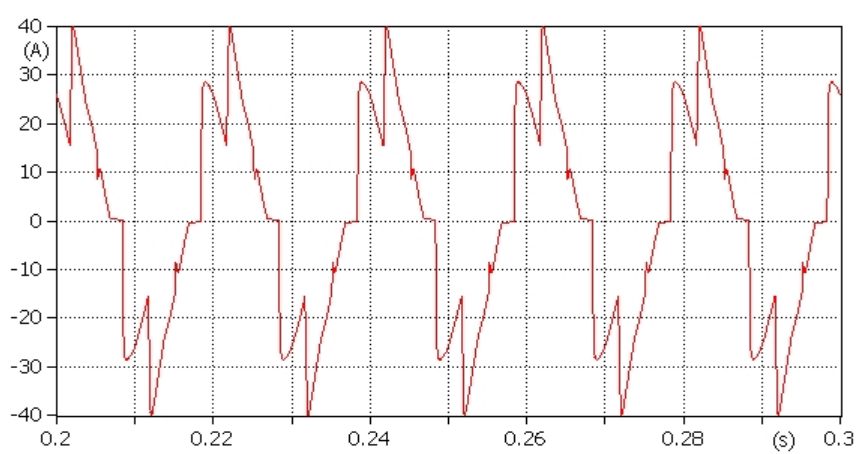

Fig. 10. Line current for phase control, all sections with firing angle 90 degrees.

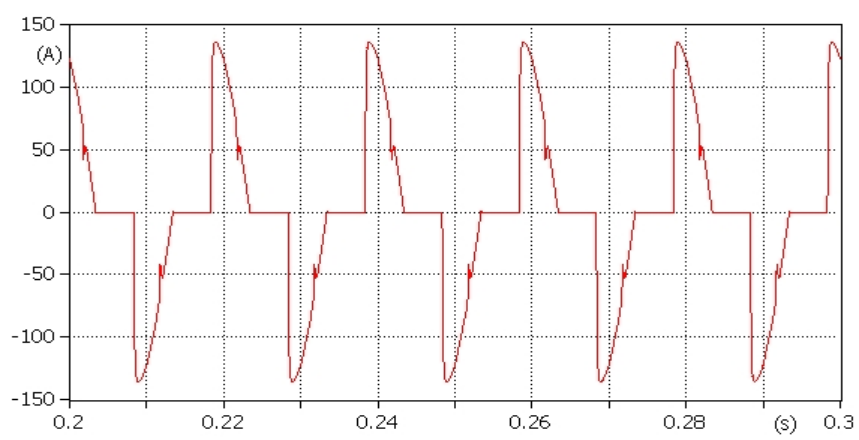

Fig. 11. Load current for phase control, one section with firing angle 90 degrees.

\section{Assessment and Designed Solution}

The numerical simulation of annealing unit with three section Both the control algorithm faces the problem with EMC for this particular equipment connected to public low voltage supply system.

Unlike of the flicker, which is generally more difficult to suppress, the phase controlled equipment is possible to equip with active filter.

TABLE IV. DEFORMED CURRENT AND DEFORMED POWER FOR NON-SYMMETRICAL THREE PHASE CONTROL, $I_{\mathrm{EQU}}=35 \mathrm{~A}$ (THREE SECTIONS IN SERVICE).

\begin{tabular}{|c|c|c|c|c|}
\hline $\begin{array}{c}\text { Firing } \\
\text { angle }\end{array}$ & \multicolumn{2}{|c|}{$\begin{array}{c}\text { Simulated RMS values of } \\
\text { input currents }\end{array}$} & \multicolumn{2}{|c|}{$\begin{array}{c}\text { Calculated values of } \\
\text { deformed power and } \\
\text { current }\end{array}$} \\
\hline$(\boldsymbol{\alpha})$ & \multicolumn{2}{|c|}{$\mathbf{( A )}$} & $\mathbf{( A )}$ & (kVA) \\
\hline & $I_{1}$ & $I$ & $I_{\mathrm{D}}$ & $S_{\mathrm{D}}$ \\
\hline 18 & 34.92 & 34.96 & 1.63 & 1.13 \\
\hline 36 & 33.72 & 33.98 & 4.14 & 2.86 \\
\hline 54 & 30.98 & 31.51 & 5.76 & 3.97 \\
\hline 72 & 26.63 & 27.32 & 6.09 & 4.20 \\
\hline 90 & 21.17 & 22.07 & 6.25 & 4.32 \\
\hline 108 & 15.15 & 16.40 & 6.27 & 4.33 \\
\hline 126 & 9.58 & 11.34 & 6.07 & 4.19 \\
\hline 144 & 4.81 & 6.54 & 4.44 & 3.06 \\
\hline 153 & 3.00 & 4.37 & 3.18 & 2.20 \\
\hline
\end{tabular}

For the active filter, which is capable of smoothing the line voltage, the most convenient place is the transformer secondary terminals, where the distortion of supply voltage is supposed to be the highest. This requires only the deform power to be covered. However, the currents are due to lower voltages higher by the transformer ratio. Besides, the value of $84 \mathrm{~V} \mathrm{AC}$ is not the standard voltage level, so the solution excludes commercially available filters [8]-[10].

\section{EXPERIMENTAL MEASUREMENTS}

The measurement was performed on the prototype of the annealing unit,. For the basic parameters assessment, see Fig. 12. The measurement was carried out using the network quality analyser BK-ELCOM, type ENA 330.11, produced by ELCOM a.s. For the reason of mutual comparison of the low frequency emission disturbances, the measurement was carried out for both full wave and phase control algorithms. The measurement was made on one section with output parameters - the nominal voltage of $80 \mathrm{~V}$ a.c., and load current of 30 A a.c. By mutual comparison of the measurement results, the small distortion of the supply network is observed, namely in the $T H D_{\mathrm{u}}$ parameter, which is caused by the low short circuit network impedance.

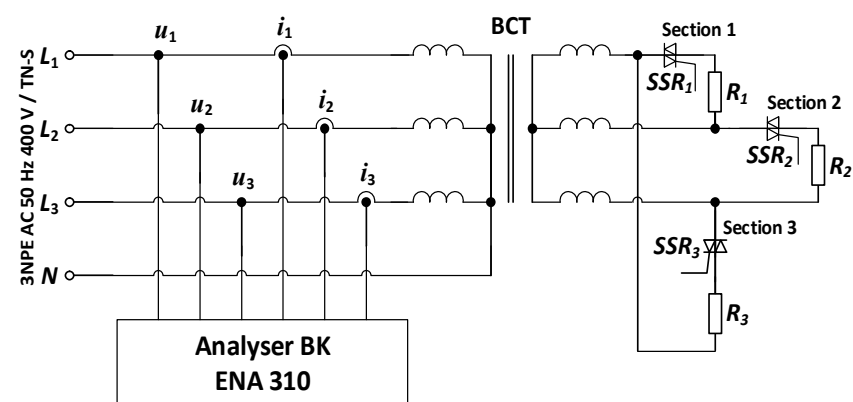

Fig. 12. Simplified scheme of the measurement stand connection.

By means of the phase control, the observed total harmonic distortion of the low voltage network was $T H D_{\mathrm{U}}=$ 2,34 \%, as seen in Fig. 13. Fig. 14 shows the total harmonic distortion of the low voltage network $T H D_{\mathrm{U}}=1,74 \%$. The measured waveforms of the phase voltages and line currents for both ways of control are shown in Fig. 15 and Fig. 16. 


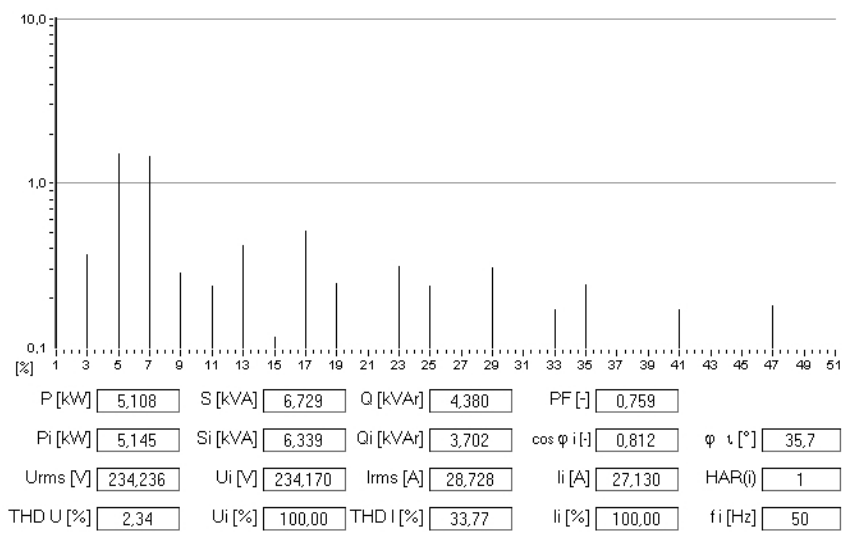

Fig. 13. Harmonic analysis of the voltage course at phase control of the annealing unit and the required current value $30 \mathrm{~A}$.

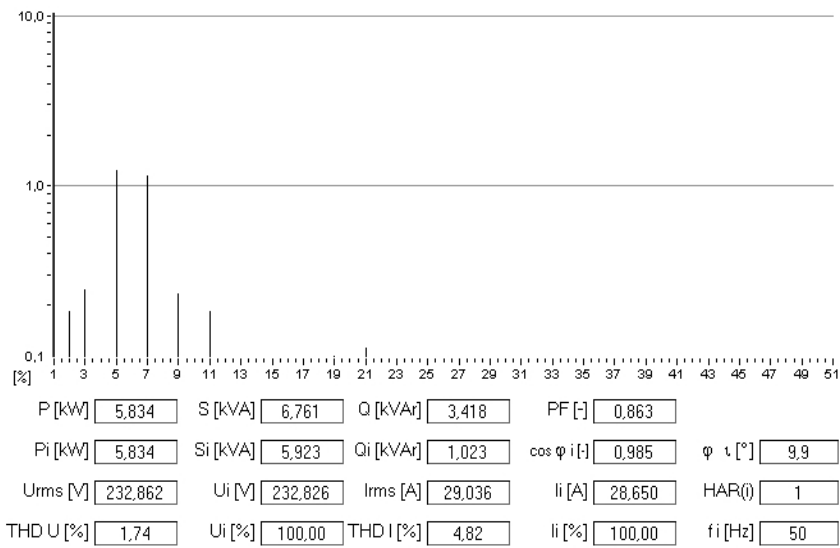

Fig. 14. Harmonic analysis of the voltage course at full-wave of the annealing unit and the required current value $30 \mathrm{~A}$.

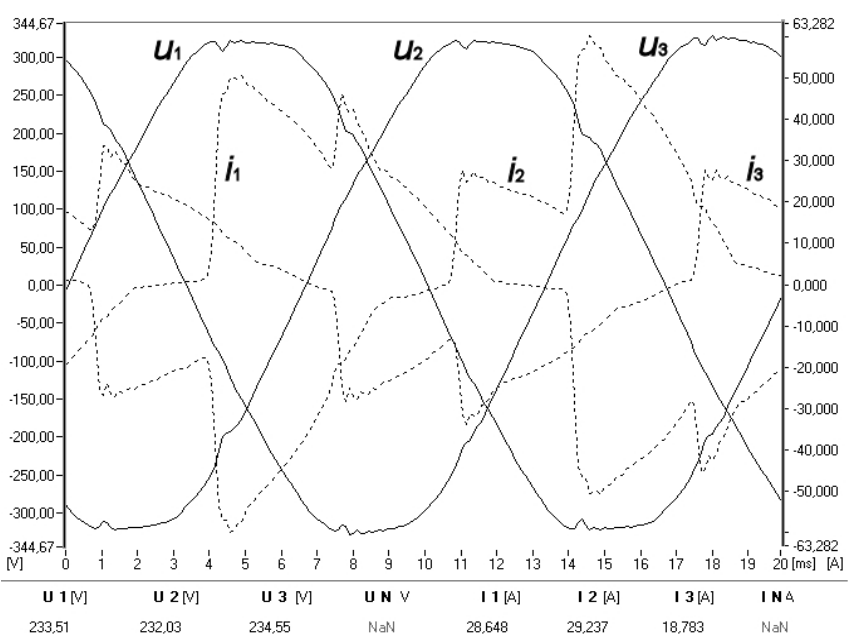

Fig. 15. Phase currents and phase voltages at phase control of the annealing unit and the required current value $30 \mathrm{~A}$.

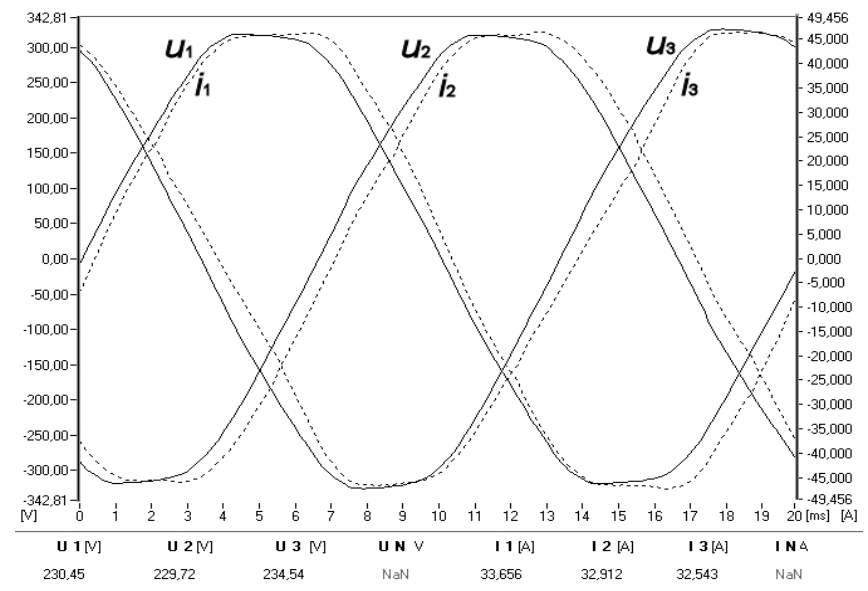

Fig. 16. Phase currents and phase voltages at full-wave of the annealing unit and the required current value $30 \mathrm{~A}$. 


\section{CONCLUSIONS}

The whole development of the annealing unit was carried out with respect to achieve the best annealing process parameters and maximum reliability as well as to minimize the disturbing effects to supply network. Newly developed Smart Annealing Unit reaches outstanding results in the annealing process. The deviation of real temperature and its required value is lower than $\pm 2{ }^{\circ} \mathrm{C}$ in the temperature range $20{ }^{\circ} \mathrm{C}$ up to $1250{ }^{\circ} \mathrm{C}$. It also has the high user comfort and is able to detect and eliminate human errors. Besides the annealing cycle, the operator only enters the value of the maximum permitted current and the whole regulation is performed adaptively. The annealing unit is short-circuit proof; it is able to detect disconnected thermoelement, disconnected heating element and other failures. It also capable to of sending email or SMS messages in case of service request. The competitive units are not able to analyse these failures and notify the operator in time. The experimental measurement carried out on the annealing unit prototype and its analyses show that in case of full-wave control, the production of harmonic current can be suppressed. Using this way of control, the flicker effect is observed, the severity of which depends on short-circuit ratio of the supply network in the point of connection. The use of phase control does not meet the requirements of EMC standards. This problem can be solved by using the active harmonic filter.

\section{REFERENCES}

[1] R. Hrbac, T. Mlcak, J. Dudek, S. Zajaczek, "The development of a modern heat treatment unit with embedded control ensuring minimal retroactive effects on the supply network", in Proc. 16th Int.
Scientific Conf. Electric Power Engineering (EPE 2015), pp. 723728, 2015. [Online]. Available: https://doi.org/10.1109/EPE.2015. 7161153

[2] Annealing unit RETEP 6S/48 and 6S/96 Hutni montaze-Svarservis, Ltd. [Online]. Available: http://www.svarservis.cz/eng/

[3] CSN EN 61000-3-11. Electromagnetic compatibility (EMC) - Part 311: Limits - Limitation of voltage changes, voltage fluctuations and flicker in public low-voltage supply systems - Equipment with rated current $<=75$ A. Praha: UNMZ, 2001, sorting signature: 333432.

[4] CSN EN 61000-3-3 ed.3. Electromagnetic compatibility (EMC) Part 3-3: Limits - Limitation of voltage changes, voltage fluctuations and flicker in public low-voltage supply systems, for equipment with rated current $<=16 \mathrm{~A}$ per phase and not subject to conditional connection. Praha: UNMZ, 2014, sorting signature: 333432.

[5] CSN EN 61000-3-12 ed.2. Electromagnetic compatibility (EMC) Part 3-12: Limits - Limits for harmonic currents produced by equipment connected to public low-voltage systems with input current 16 A and 75 A per phase. Praha: UNMZ, 2011, sorting signature: 333432 .

[6] CSN EN 61000-4-15 ed.2. Electromagnetic compatibility (EMC) Part 4-15: Testing and measurement techniques - Flickermeter Functional and design specifications. Praha: UNMZ, 2012, sorting signature: 333432 .

[7] IEEE Std $1453^{\mathrm{TM}}-2015$, IEEE Recommended Practice for the Analysis of Fluctuating Installations on Power Systems. New York, 2015, NY 10016-5997.

[8] J. Wosik, A. Kozlowski, M. Habrych, M. Kalus, B. Miedzinski, "Study on performance of non-linear reactive power compensation by using active power filter under load conditions", Elektronika Ir Elektrotechnika, vol. 22, pp. 19-23, [Online]. Available: http://dx.doi.org/10.5755/j01.eee.22.1.14098

[9] R. Hou, J. Wu, Y. C. Liu, D. G. Xu, "Generalized design of shunt active power filter with output LCL filter", Elektronika Ir Elektrotechnika, vol. 20, no. 5, pp. 65-71, 2014. [Online]. Available: http://dx.doi.org/10.5755/j01.eee.20.5.3910

[10] M. Bartlomiejczyk, S. Mirchevski, "Reducing of energy consumption in public transport - results of experimental exploitation of super capacitor energy bank in Gdynia trolleybus system", 16th Int. Power Electronics and Motion Control Conf. and Exposition, (PEMC 2014), pp. 94-101, 2014. [Online]. Available: http://dx.doi.org/ 10.1109/EPEPEMC.2014.6980616 